\title{
Penentuan Kinerja Sistem SCADA PT.PLN (Persero) Unit Pelaksana Pengatur Beban Area Jakarta dan Banten Berdasarkan Nilai Mean Time To Repair
}

\author{
Dewi Astuti ${ }^{1}$, Kun Fayakun ${ }^{2)}$, Harry Ramza ${ }^{3)}$ \\ 1,2,3)Program Studi Teknik Elektro, FakultasTeknik \\ Universitas Muhammadiyah Prof. Dr. Hamka \\ Jalan Tanah Merdeka No. 6, Kp Rambutan, Jakarta13830 \\ Telp : +62-218400941, Faks : +62-2187782739 \\ Email.: dewiastuti0107@gmail.com, knfayakun@gmail.com, hramza@uhamka.ac.id
}

\begin{abstract}
Abstrak - Sistem SCADA dan Telekomunikasi yang dibentuk dari sub sistem teleinformasi data yang merupakan rangkaian perangkat dan dapat menghasilkan fungsi power sistem untuk dikontrololeh sub sistem master station pada yang terdapat pada kontrol center. Dalam menjalankan fungsinya setiap peralatan pada masing - masing sub sistem harus dapat memberikan layanyan dari segi kualitas dan kuantitas hal tersebut dapat diukur melalui kinerja. Target kinerja pengusahaan yang telah ditetapkan merupakan kesanggupan unit pelaksana pengatur beban yang memberikan hasil layanan (availability) berupa fungsi sub sistem yang di dapat melalui perhitungan nilai MTTR(Mean Time To Repair) pada masing - masing sub sistem selama periode triwulan (satu tahun anggaran). Dari hasil penentuan kinerja sistem SCADA PT.PLN (Persero) unit pelaksana pengatur beban area Jakarta dan Banten untuk periode III (Juli, Agustus, September) tahun 2020 diperoleh tingkat availability teleinformasi data sebesar 99,27\%, dan nilai availability master station sebesar 99,99\% Serta nilai Availability sistem SCADA dan Telekomunikasi sebesar 99.63\%. Dimana hasil yang dicapai dari periode triwulan III telah mencapai tolak ukur dari persyaratan perusahaan yaitu 99,5\%.
\end{abstract}

Kata kunci: $S C A D A, M T T R$, Availability.

\section{PENDAHULUAN}

Teknologi sistem Tenaga listrik semakin berkembang pesat pada saat ini. Perkembangan tersebut didasari pada kebutuhan pemakaian listrik yang selalu meningkat setiap tahunnya. Kebutuhan akan ketersediaan listrik dengan kinerja yang optimal untuk mengatasi kapasitas pemakaian yang memadai. Pemakaian listrik pada setiap konsumen yang bersifat pribadi (RumahTangga) atau pun berkelompok (pabrik ataupun perusahaan yang menggunakan daya listrik yang besar).

SCADA ( Supervisory Control And Data Acquisition) [1][2] difungsikan untuk memaksimalkan pemakaian daya listrik secara efisien dengan cara mengontrol, memonitoring, serta mentransmisikan daya listrik secara merata sesuai dengan kebutuhan pemakaian konsumen. Dalam mengontrol aliran daya listrik melalui sistem SCADA pasti akan terjadi kejadian kegagalan dalam sistem seperti Downtime peralatan ataupun gangguan lain darisistem SCADA seperti kegagalan server, workstation, dan Link Telekomunikasi. [3] Hal ini berpengaruh pada parameter kinerja sistem SCADA seperti daya yang harusnya di transfer dari gardu induk lain yang tidak terjadi gangguan ke gardu induk yang sedang terjadi gangguan hal ini dilakukan untuk mengcover ketersediaan listrik dari gardu induk yang mengalami kegagalan untuk menghindari terjadinya Blackout (Pemadamanlistrik). [4] Untuk meminimalisir keadaan tersebut maka dilakukan perhitungan Availability dari sistem SCADA agar nilai keandalan dari masing masing infrastruktur pendukung sistem SCADA dapat memenuhi standar kinerja yang telah di tentukan oleh PT.PLN (Persero) sebagai perusahaan penyedia listrik nasional.

Pada penelitian sebelumnya,[5] membahas tentang perhitungan kinerja pada sistem teleinformasi data dan master station. Kedua sub sistem tersebut merupakan rangkaian yang menghasilkan fungsi yang digunakan untuk mengoperasikan power sistem dengan frekuensi $50 \mathrm{~Hz}$. Pada keandalan telekomunikasi data[6]. Untuk mengendalikan sistem tenaga listrik yang besar seperti halnya sistem SCADA Jawa- Bali di perlukan sarana telekomunikasi yang handal dan memadai agar data dan informasi yang diperlukan untuk mengontrol operasional bisa di kendalikan dengan cepat. 
Dari latar belakang penelitian diatas, maka tugas akhir ini akan menetukan kinerja sistem SCADA dan Telekomunikasi area Jakarta - Banten. Dengan cara mencari nilai Mean Time To Failure dan Mean Time Between Failure dengan menggunakan nilai Mean Time To Repair yang dari data kegagalan sistem SCADA untuk periode Triwulan III 2020.

\section{METODE}

Padasistem SCADA sub sistem teleinformasi data mengacu pada peralatan gateway, remote terminal Unit (RTU) dan Intelligent Electronic Device (IED) sebagai peralatan yang dapat di kontrol langsung oleh operator peralatan ini dapat mempengaruhi aktifitas real time serta keandalan sistem SCADA dalam mengendalikan sistem tenaga listrik jika terjadi gangguan. Untuk itu diperlukan adanya perhitungan kinerja pada peralatan untuk dapat menghindari kejadian yang diakibatkan oleh terganggunya peralatan - peralatan tersebut. Dalam standar[7] telah ditetapkan perhitungan kinerja pada sistem teleinformasi data dengan persamaan sebagai berikut :
a. Telemetering $(\mathrm{TM})=$ bobot 1
b. Telesignalling $(\mathrm{TS})=$ bobot 1
c. Remote Control $(\mathrm{RC})=$ bobot 1

Perhitungan availability (kinerja) teleinformasi data :

Dimana

$$
\text { AVTD }=\left[1-\frac{\Sigma(\text { Tm }, T s, R c) \text { Down Time }}{N(\text { Tm,Ts,Rc }) X \text { Ttotal }}\right] \times 100 \%
$$

Down time : Jumlah waktu telemetering yang tidak TM available (invalid) per triwulan dalam (Telemetring) satuan jam.

Down time TS : Jumlah waktu TS yang tidak available (Telesinyaling) (invalid) per triwulan dalam jam.

Down time RC : Jumlah waktu RC yang tidak (Remote available (invalid) per triwulan dalam Control)

$\mathrm{N}$

(TM .Ts , Rc )

T.total jam.

Jumlah Tm,Ts,Rc yang ada per akhir triwulan pada periode sebelumnya.

Waktu dalam kurun I triwulan (3 bulan ).

Master Station[8] merupakan tempat pemrosesan kontrol antara gardu induk dan dispatcher yang saling terhubung. Yang artinya sebelum gardu induk dapat di kontrol langsung oleh dispatcher master station yang akan melakukan semua parameter test seperti telesinyal, telekontrol, dan telemetering. Begitupun sebaliknya jika terjadi gangguan pada saat pengontrolan seperti peralatan yang terdapat pada gardu induk tidak dapat dikontrol oleh operator maka master station yang akan langsung berkomunikasi ke gardu induk dan dispatcher untuk melakukan tindakan pencegahan seperti peralihan peralatan untuk mencegah timbulnya masalah yang diakibatkan oleh terlambatnya pengontrolan.

Untuk itu perhitungan kinerja pada peralatan master station sangat diperlukan sebagai media penghubung antara dispatcher dan gardu induk[9]. Dalam standar SPLN S7.001 : 2008 telah ditetapkan standarisasi untuk perhitungan kinerja master station dengan menggunakan persamaan sebagai berikut:

$$
\begin{array}{ll}
\text { a. } & \text { Server }(\mathrm{SV})=\text { bobot } 4 \\
\text { b. } & \text { Workstation }(\mathrm{WS})=\text { bobot } 1,5 \\
\text { c. } & \text { Switch }(\mathrm{SW})=\text { bobot } 2 \\
\text { d. } & \text { Peripheral }(\mathrm{PH})=\text { bobot } 0,5 \\
\text { e. } & \text { UPS }=\text { bobot } 2
\end{array}
$$

Perhitungan availability Master Station :

AVMS $=\left[1-\frac{(\text { Tsv } \times 4)+(\text { Tws } \times 1,5)+(\text { Tws } \times 2)+(\text { Tph } \times 0,5)+(\text { Tups } \times 2)}{N(\text { SV,WS, SW, PH, UPS }) X \text { Ttotal }}\right] \times 100 \%$

Untuk sistem Redundant

$$
A V_{M S}=1-((1-\mathrm{AV} 1)-(1-\mathrm{AV} 2)) \ldots(2 \mathrm{c})
$$

Perhitungan availability konsep Redundant yang artinya selain menggunakan persamaan diatas untuk menghitung secara manual,[10] kinerja subsistem master station juga dapat dihitung menggunakan persamaan persamaan $2 \mathrm{a}$, dan $2 \mathrm{~b}$ untuk menghitung kinerja sistem yang bersifat redundant, dimana :
$\mathrm{T}_{\mathrm{sv}}$
: Jumlah waktu server yang tidak available per triwulan (3 bulan) dengan satuan jam
$\mathrm{T}_{\mathrm{sw}}$
$\mathrm{T}_{\mathrm{PH}}$
$\mathrm{AV}_{1}$
$\mathrm{AV}_{2} \quad: \quad$ Availability sistem 2
$\mathrm{T}_{\text {total }} \quad:$ Waktu dalam kurun waktu triwulan (3 bulan).
N : Jumlah SV,WS,SW,PH dan PS (SV,WS,SW,PH yang ada per akhir triwulan pada dan PS) 
Perhitungan Availability Master Station dihasilkan oleh aplikasi offline di masing - masing UP2B. Jumlahnya dalam satuan \%.

Pemberian bobot pada masing-masing fungsi peralatan tergantung pada peralatan yang memiliki peran paling penting dalam beroperasi. Contohnya antara server dan peralatan peripheral memiliki bobot yang berbeda jika bobot server bernilai 4 dan peralatan peripheral bernilai 0,5 artinya server yang memiliki peranan penting dalam operasi realtime.[11] Hal ini dikarenakan setiap pertukaran informasi antara gardu induk dan kontrol center harus melewati server jika terjadi gangguan pada server atau server down maka seluruh proses realtime normal akan terhenti. Namun jika peralatan peripheral seperti power supply genset atau switch yang terganggu atau down maka hal tersebut masih dapat di backup oleh server dan langsung dapat digantikan oleh peralatan cadangan lainnya.

\section{PEMBAHASAN}

\subsection{Perhitungan Pada subsistem Teleinformasi data.}

Yang termasuk dalam subsistem Teleinformasi data adalah RTU (remote terminal unit) [12] dengan perhitungan nilai MTTR menggunakan persamaan :

$$
\text { AVTD }=\left[1-\frac{\Sigma(T m, T s, R c) \text { Down Time }}{N(T m, T s, R c) X \text { Ttotal }}\right] \times 100 \%
$$

Data Realisasi pemeliharaan dan perbaikan sistem SCADA yang diperoleh pada periode triwulan III tahun 2020 di perlihatkan pada tabel 3.1 berikut ini :

\begin{tabular}{ccccc}
\multicolumn{4}{c}{ Tabel.3. 1 Rekapkegagalanteleinformasi data } \\
\hline \multirow{4}{*}{ Periode III 2020 } \\
\hline \multirow{4}{*}{ RTU } & Kalian & gangguan & $\begin{array}{c}\text { Time } \\
\text { Verifikasi } \\
\text { MTTR }\end{array}$ & $\begin{array}{c}\text { Total } \\
\text { Hours }\end{array}$ \\
\cline { 2 - 5 } & Juli & 20433 & 2,231 & 744 \\
& Agustus & 20305 & 11,679 & 744 \\
September & 121,848 & 2,185 & 720 \\
\hline Jumlah & 40859,848 & 16,094 & 2208
\end{tabular}

Berdasarkan tabel 3.1 diatas perhitungan tingkat Availability periode Triwulan III tahun 2020 sebagai berikut:

$$
\begin{gathered}
\text { AVTD }=\left[1-\frac{\sum(\text { Tm,Ts,Rc Down Time }}{N(\text { Tm,Ts,Rc }) \text { Ttotal }}\right] \times 100 \% \\
=\left[1-\frac{(40859,848 \times 16,094)}{40859,848 \times 2208}\right] \times 100 \% \\
=\left[1-\frac{657609,9218}{90218544}\right] \times 100 \%
\end{gathered}
$$

Copyright (C) 2020 FT-UHAMKA. - All rights reserved DOI: 10.22236/teknoka.v5i.357

$$
\begin{aligned}
& =1-0,007289077 \times 100 \% \\
& =0,992710923 \times 100 \% \\
& =99,271 \%
\end{aligned}
$$

Berdasarkan Perhitungan Availability periode triwulan III tahun 2020 sebesar 99,27 \% yang masih dibawah tolak ukur yang ditentukan yakni $99,5 \%$ untuk Nilai Target kinerja pengusahaan pada masing-masing subsistem.

\subsection{Perhitungan Pada subsistem Master Station.}

Yang termasuk perhitungan subsistem master station dan semua jenis peralatan peripheralnya dengan menghitung Time verifikasi MTTR dan pemeliharaan

\begin{tabular}{|c|c|c|c|}
\hline \multirow{2}{*}{ Device } & \multicolumn{3}{|c|}{ Timeverifikasi MTTR } \\
\hline & Juli & Aguss & Sept \\
\hline \multicolumn{4}{|l|}{ Server } \\
\hline Server SCADA 1 & 0 & 0 & 0 \\
\hline Server SCADA 2 & 0 & 0 & 0 \\
\hline Server EMS 1 & 0,086 & 0,209 & 0,086 \\
\hline Server EMS 2 & 0,146 & 0,191 & 0,146 \\
\hline Server Historikal Data 1 & 0 & 0 & 0 \\
\hline Server Historikal Data 2 & 0 & 0 & 0 \\
\hline Server Komunikasi 1 & 0,060 & 0,416 & 0,060 \\
\hline Server Komunikasi 2 & 0,106 & 0 & 0,106 \\
\hline Server Offline & 0 & 0 & 0 \\
\hline \multicolumn{4}{|l|}{ Workstation dan Peripheral } \\
\hline Workstation Dispatcher 1 Metro & 0 & 0 & 0 \\
\hline Workstation Dispatcher 2 Metro & 0 & 0 & 0 \\
\hline Workstation Dispatcher 3 Metro & 0 & 0 & 0 \\
\hline Workstation Dispatcher 1 Banten & 0 & 0 & 0 \\
\hline Workstation Dispatcher 2 Banten & 0,098 & 2,963 & 0,098 \\
\hline Workstation Dispatcher 3 Banten & 0 & 0 & 0 \\
\hline Workstation Dispatcher 3 / Penyelia & 0 & 0 & 0 \\
\hline Switch 1 & 0 & 0 & 0 \\
\hline Switch 2 & 0 & 0 & 0 \\
\hline UPS 1 & 0 & 0 & 0 \\
\hline UPS 2 & 0 & 0 & 0 \\
\hline Peripheral (PAC 1) & 0 & 0 & 0 \\
\hline Peripheral (PAC 2) & 0 & 0 & 0 \\
\hline Peripheral (GPS 1) & 0 & 0 & 0 \\
\hline Peripheral (GPS 2) & 0 & 0 & 0 \\
\hline
\end{tabular}
dengan menggunakan persamaan :

$$
\text { AVMS }=\left[1-\frac{(\text { Tsv } x 4)+(\text { Tws } x 1,5)+(\text { Tws } \times 2)+(\text { Tph } \times 0,5)+(\text { Tups } \times 2)}{N(\text { SV,WS, SW, PH,UPS }) \times \text { Ttotal }}\right] \times 100 \%
$$

Dari data realisasi dan pemeliharaan yang di peroleh pada periode III tahun 2020 yang di perlihatkan pada tabel 3.2 berikut :

Tabel.3. 2 Rekap Gangguan dan pemeliharaan 
Berdasarkan tabel 3.2 diatas perhitungan tingkat Availability periode Triwulan III tahun 2020 sebagai berikut:

$$
\begin{aligned}
& \text { AVMS }=\left[1-\frac{(\text { Tsv } \times 4)+(\text { Tws } \times 1,5)+(\text { Tws } \times 2)+(\text { Tph } \times 0,5)+(\text { Tups } \times 2)}{N(\text { SV,WS,SW,PH,UPS }) \times \text { Ttotal }}\right] \times 10 \\
& \begin{aligned}
\text { AV1 }=[1 & \left.-\frac{((0,086 \times 4)+(0,06 \times 4)+(0,098 \times 1,5)))}{11 \times 2208}\right] \times 100 \% \\
= & {\left[1-\frac{0.584}{24288}\right] \times 100 \% } \\
& =0,99997 \times 100 \%=99,997 \%
\end{aligned}
\end{aligned}
$$

AV2

$$
\begin{aligned}
=[1 & \left.-\frac{((0,146 \times 4)+(0,106 \times 4)+(0,098 \times 1,5)))}{11 \times 720}\right] \times 100 \% \\
& =\left[1-\frac{1,155}{24288}\right] \times 100 \%==0,9995 \times 100 \% \\
& =99,995 \%
\end{aligned}
$$

$$
\begin{aligned}
A V_{M S} & =1-((1-\mathrm{AV} 1)-(1-\mathrm{AV} 2)) \\
& =(100-(100-99,997)-(100-99,995) \\
& =99,99 \%
\end{aligned}
$$

Berdasarkan Perhitungan Availability master station periode triwulan III tahun 2020 sebesar 99,99 \% nilai ini telah melampaui target kinerja subsistem yang ditentukan yakni 99,5\% untuk Nilai Target kinerja pengusahaan pada masing -masing subsistem.

\subsection{Perhitungan Kinerja Sistem SCADA dan Telekomunikasi.}

Dari data perhitungan availability pada subsistem[13] teleinformasi data dan subsistem master station diatas, maka kinerja sistem SCADA dan telekomunikasi adalah :

$$
\text { AVSCADATEL }=\frac{A V T D+A V M S}{2}
$$

Untuk data kinerjaSistem SCADA dan Telekomunikasi periode Triwulan III Tahun 2020 dapat dilihat hasil perhitungan availability sub sistem SCADA dan Telekomunikasi pada tabel 3.3 berikut ini :

Tabel.3. 3 Perhitungan Kinerja Sistem SCADA dan Telekomunikasi

\begin{tabular}{clc}
\hline \multicolumn{2}{c}{ Subsistem } \\
\hline 1 & Teleinformasi Data & $99,27 \%$ \\
2 & Master Station & $99,99 \%$ \\
& AV SCADA \& & $99,63 \%$ \\
& TELEKOMUNIKASI \\
\hline
\end{tabular}

Copyright (C) 2020 FT-UHAMKA. - All rights reserved DOI: 10.22236/teknoka.v5i.357

\section{KESIMPULAN}

Kinerja yang telah di tetapkan merupakan kesanggupan unit pelaksanaan agar dapat memberikan layanan listrik yang memadai berupa fungsi subsistem yang memiliki kinerja yang optimal.

Dari hasil perhitungan availability sistem SCADA dan Telekomunikasi PT.PLN (Persero) Unit Pelayanan Pengatur Beban Area Jakarta dan Banten periode III tahun 2020 untuk subsistem teleinformasi data 99,27\% dan subsistem master station $99,99 \%$. Dan untuk itu didapat nilai Availability sistem SCADA dan telekomunikasi periode III tahun 2020 sebesar 99,63\%. Nilai ini telah melewati target kinerja SCADATEL yaitu $99,5 \%$.

\section{KEPUSTAKAAN}

[1] U. Indonesia, R. Novel, F. Teknik, U. Indonesia, P. Studi, and T. Elektro, "KELISTRIKAN UNIVERSITAS INDONESIA," 2009.

[2] M. G. Suitella, "MEDIA KOMUNIKASI PADA SCADA PT . PLN APD JAKARTA RAYA DAN TANGERANG," pp. 1-7.

[3] H. Zhao, L. Ma, X. Yan, and D. A. N. Y. Zhao, "Sejarah Multi-Stasiun SCADA Kompresi Data dari Distribusi Berbasis Sistem Manajemen pada Tensor Tucker penguraian," vol. 7, pp. 390-396, 2019, doi: 10.1109/ACCESS.2019.2937383.

[4] L. N. Hurlatu, L. S. Patras, and G. M. C. Mangindaan, "Analisa Perancangan Sistem SCADA Di Sistem Kelistrikan Minahasa," vol. 5, no. 2, 2016.

[5] P. Studi, P. Pertanian, and P. Gorontalo, "ANALISA KINERJA SISTEM SCADA DAN TELEKOMUNIKASI DI PT . PLN UNIT PENYALURAN DAN PUSAT PENGATURAN BEBAN GORONTALO," vol. 7, no. 1, pp. 1-5, 2017.

[6] A. W. Hasanah, "KEANDALAN MONITORING TELEKOMUNIKASI DATA MENGGUNAKAN SERAT OPTIK DALAM PENGENDALIAN."

[7] D. Aribowo and M. Otong, "Remote Terminal Unit ( RTU ) SCADA Pada Jaringan Tegangan Menengah $30 \mathrm{KV}$," vol. 3, no. 2, pp. 2-7, 2014.

[8] P. Bonar, Teknologi Sistem Pengendalian Tenaga Listrik Berabasis SCADA. Jakarta: 1999.

[9] D. Iskandar, "Sistem informasi gardu induk dan gardu distribusi pln," vol. 2011, no. 
semnasIF, pp. 26-31, 2011.

[10] M. Hasan, S. Anggota, and D. A. N. H. T. Mouftah, "Optimal Sistem Penempatan Trust di Smart Grid SCADA Jaringan," vol. 4, pp. 2907-2919, 2016, doi:

10.1109/ACCESS.2016.2564418.

[11] M. Jurusan, T. Elektro, U. Tadulako, D. Jurusan, and T. Elektro, "EVALUASI

PENGGUNAAN SCADA PADA

KEANDALAN SISTEM DISTRIBUSI," vol. 1, no. 1, 2014.
[12] I. Pujotomo, "Implementasi Sistem SCADA Untuk Pengendalian Jaringan Distribusi 20 KV," vol. 1, no. 1, pp. 51-66, 1980.

[13] P. Bunga, I. Martinus, P. Mt, S. Silimang, and S. T. Mt, "Perancangan Sistem Pengendalian Beban Dari Jarak Jauh Menggunakan Smart Relay,”vol. 4, no. 5, 2015. 